\title{
Redo Hypospadias Repair: Our Experience in a Tertiary Care Centre
}

\author{
Shoubhik Chandra ${ }^{1}$, Priyeshkumar Patel $^{1}$, Rajendra Nerli ${ }^{1,2,{ }^{*}, \text { Shridhar Ghagane }^{2} \text {, Neeraj Dixit }}{ }^{2}$ \\ ${ }^{1}$ Department of Urology, JN Medical College, KLE Academy of Higher Education \& Research (Deemed-to-be-University), JNMC Campus, \\ Belagavi, Karnataka, India \\ ${ }^{2}$ Department of Urology, KLES Kidney Foundation, KLES Dr. Prabhakar Kore Hospital \& Medical Research Centre, Nehru Nagar, Belagavi, \\ Karnataka, India
}

Email address:

rbnerli@gmail.com (R. Nerli)

${ }^{*}$ Corresponding author

\section{To cite this article:}

Shoubhik Chandra, Priyeshkumar Patel, Rajendra Nerli, Shridhar Ghagane, Neeraj Dixit. Redo Hypospadias Repair: Our Experience in a Tertiary Care Centre. International Journal of Clinical Urology. Vol. 5, No. 1, 2021, pp. 43-46. doi: 10.11648/j.ijcu.20210501.19

Received: February 16, 2021; Accepted: May 8, 2021; Published: May 31, 2021

\begin{abstract}
Introduction: Treating children following a failed hypospadias repair can be challenging. Complications include urethrocutaneous fistulas, glans dehiscence, meatal stenosis and urethral strictures. Glans dehiscence remains the most common indication for re-operative urethroplasty. The repair can be challenging because of several factors including significant scarring and paucity of genital skin. We report our experience in the management of failed hypospadias repairs at our centre. Materials \& Methods: We retrospectively reviewed and analysed the inpatient and outpatient records of children/adolescents undergoing redo-hypospadias repairs during the period Jan 2010 to Dec 2019. Results: A total of 37 children with a mean age of $8.62 \pm 3.76(2-17)$ years underwent a redo repair of hypospadias. Twenty children underwent two stage buccal mucosa urethroplasty, 11 underwent tubularized incised plate (TIP) urethroplasty, 5 dorsal inlay graft urethroplasty and 1 onlay flap urethroplasty. A total of three (8.10\%) children developed an urethrocutaneous fistula needing an additional stage for repair. Uroflowmetry done in all children showed adequate maximum flow rates, with minimal to nil residuals. Conclusions: The majority of hypospadias failures can be salvaged with one stage surgery including Mathieu flip flap Urethroplasty, Tubularized incised plate urethroplasty and dorsal inlay graft urethroplasty. A two stage buccal mucosa urethroplasty may be necessary in cases wherein the urethral plate or skin substitute is grossly scarred, or the ventral curvature greater than 30 degrees. Complications do occur following redo procedures but eventually excellent functional and cosmetic results can be achieved.
\end{abstract}

Keywords: Failed Hypospadias, Penile Stricture, Glans Dehiscence, Urethrocutaneous Fistula, Chordee

\section{Introduction}

Urethrocutaneous fistulas, glans dehiscence, meatal stenosis and urethral strictures remain the common complications following hypospadias repair, however glans dehiscence is the most common indication for re-operative urethroplasty. Irrespective of what surgical procedure is done, it is very important to make a correct and systematic decision. [1] Experts in the field have suggested several tips in the repair of redo-hypospadias. TIP (tubularized incised plate) urethroplasty remains the first choice in cases wherein the urethral plate is present and is not grossly scarred. Graft inlay would be the preferred choice in cases, where the plate has been excised but a skin strip without gross scarring remains. Whenever the urethral plate is grossly scarred or when the ventral curvature (VC) is greater than 30 degrees, a two-stage procedure with oral mucosa grafting is preferred.

The repair of a failed hypospadias surgery can be challenging because of several factors including significant scarring and paucity of genital skin. The treating surgeon is left with less than ideal material with which to reconstruct the patient. [2] Snodgrass and Lorenzo reported their initial experience of using TIP urethroplasty in 15 patients with a mean follow-up of 5 months. They achieved a cosmetically normal meatus in 13 of 15 patients and complications 
comprised 2 fistulae and 1 glans dehiscence. [3] Similarly Borer and colleagues [4] also used TIP in 25 redo cases with satisfactory results, and complications included 5 fistulae and 1 meatal stenosis. In this study we report our experience in the management of failed hypospadias repairs at our centre.

\section{Materials \& Methods}

With the approval of the institutional/University ethical and review committee, we retrospectively reviewed and analysed the inpatient and outpatient records of children/adolescents undergoing redo-hypospadias repairs during the period Jan 2010 to Dec 2019. A detailed history of all patients was noted. Previous surgical notes and type of repairs performed were thoroughly noted and studied. Examination findings such as the length of penis, shape of glans, diameter of glans, width of urethral plate, presence of urethrocutaneous fistula, chordee, and previous scars were noted. The patient's subjective opinion regarding the penile curvature if present was also noted. Photographs of chordee were also evaluated. Uroflowmetry graphs were also analysed.

\section{Results}

During the study period of ten years a total of 37 children with a mean age of $8.62 \pm 3.76(2-17)$ years underwent a redo repair of hypospadias. The site of hypospadias was proximal in 22, mid penile in 8 and distal in the remaining 7 at the time of first repair. The average number of failed repairs was $2.29 \pm 0.66$ (range $2-6$ ). Three children had urethrocutaneous fistula, 6 had persistent chordee $\left(>30^{\circ}\right)$, complete dehiscence with absent urethral plate in 14 , and stricture in four.

Table 1. Surgical options used for REDO hypospadias.

\begin{tabular}{lll}
\hline $\begin{array}{l}\text { Sl. } \\
\text { No. }\end{array}$ & $\begin{array}{l}\text { Procedure and number of } \\
\text { children (37) }\end{array}$ & Complications \\
\hline 1 & Two stage buccal mucosa & Graft contraction $>30 \%$ (3) \\
2 & urethroplasty (20) & Fistula (2) \\
3 & TIP urethroplasty (11) & Fistula (1) \\
4 & Onsal inlay graft urethroplasty (5) urethroplasty (1) & - \\
\hline
\end{tabular}

All the 14 children with absent and severely scarred urethral plate and the six children with a ventral chordee of $>30^{\circ}$ underwent a two staged buccal mucosa urethroplasty (Table 1). The scarred urethral plate, scar tissue was excised in all, and chordee corrected. Buccal mucosal grafts were harvested from cheek in all and additionally from lower lip in two. The grafts contracted more than $30 \%$ in three children needing an additional buccal mucosal graft inlay in the second stage along with urethroplasty. None of these 20 children had any major complications. Two children had darkening of the skin margins needing no active treatment and healed by itself. The urethral catheter was left in place for two weeks in these two children.

Eleven children underwent TIP repair (Figure 1). Of these
11 children, four children underwent buccal mucosa graft inlay in the glanular area so as to achieve meatus at the tip. Two children developed an urethrocutaneous fistula needing repair. Five children who had reasonably well maintained urethral plate, underwent dorsal inlay graft urethroplasty (Figure 2). One child developed an urethrocutaneous fistula. This fistula was repaired in another sitting. One child who had a narrow urethral plate, underwent a penile skin onlay procedure.

A total of three $(8.10 \%)$ children developed an urethrocutaneous fistula needing an additional stage for repair. The average follow-up was 45 months. The mean penile perception scores (PPS) as scored by the parents of all children was $13 \pm 0.81$. The outcomes of surgery were well accepted by the parents. Uroflowmetry done in all children showed adequate maximum flow rates, with minimal to nil residuals.
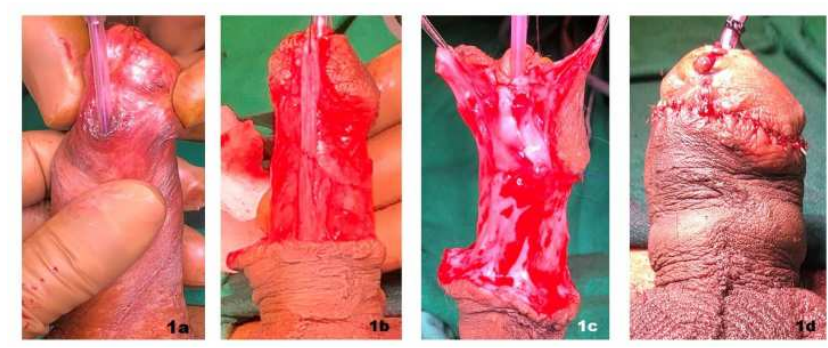

Figure 1. $a, b, c$ : Showing the steps of TIP urethroplasty.
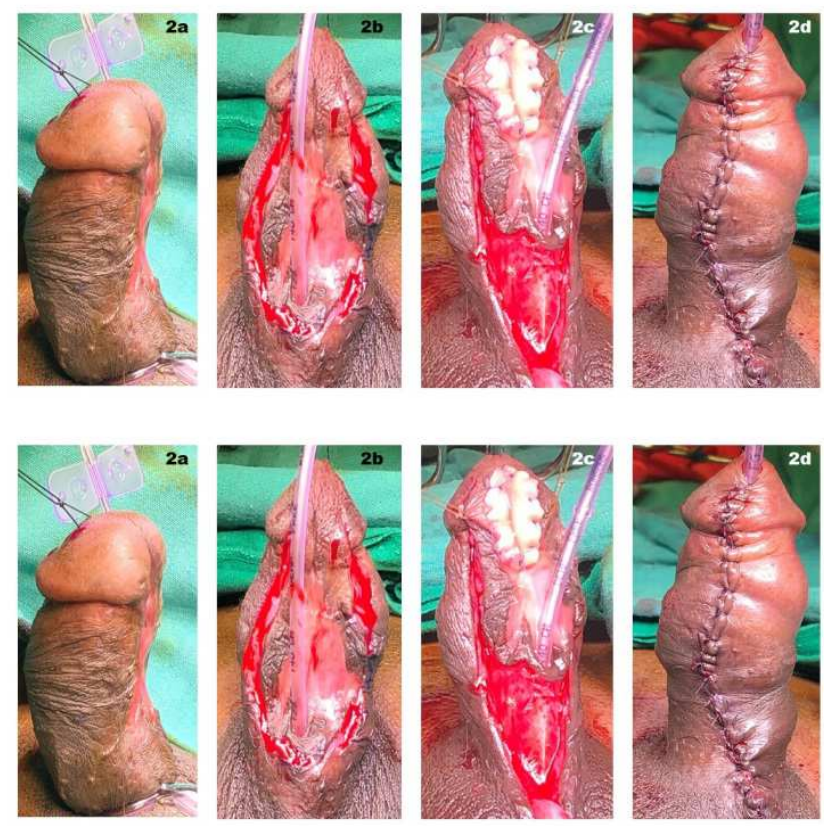

Figure 2. a. showing Gittes test. b. Incision made around the urethral plate consisting of buccal mucosa. c. Buccal mucosa inlay graft in the glanular area. d. repair complete.

\section{Discussion}

It has become essential to repair all cases of hypospadias irrespective of the presence or absence of chordee or the position of the meatus including the glanular variety. Despite 
the development of several new surgical techniques, optical magnification and the use of fine suture material, complications and failures are still encountered, requiring reoperation. [5, 6] Failure following hypospadias repair represents a matter of dilemma and concern to the treating surgeons as the previous repairs would have led to scarring and consumption of local tissues. [7] The type of repair depends on the availability of local tissue and the degree of tissue scarring. It is even more challenging for a surgeon to have a repeat failure, especially in the event of significant tissue scarring and the paucity of local genital skin. A large majority of hypospadias cripples would have had more than 3 failed prior attempts at urethroplasty. [8] Several salvage techniques have been reported and suggested, including the parameatal flap of Mathieu, onlay island flap, TIP urethroplasty and use of free grafts. [5]

The versatility of Mathieu urethroplasty as salvage procedure to repair a hypospadias has been confirmed in the literature. [9-13] Simmons and colleagues [9] used Mathieu flip-flap in 17 repairs and had a successful salvage in $83 \%$ of their patients using a single procedure. Secrest et al. [12] pointed out that impaired vascularity, crossed suture lines and scarring were factors that could impede the use of the Mathieu procedure as a salvage operation. Anwar et al [13] modified the Mathieu's procedure by creating a wide subdermal vascular dartos pedicle attached to the perimeatalbased flap, and urethroplasty was accomplished using running inverted subcuticular sutures, and the urethral suture lines were covered by fanning out the redundant dartos pedicle over the repair. They reported the use of modified Mathieu urethroplasty for salvage hypospadias repair in 38 children aged between 2 and 10 (mean 5) years. Follow-up ranged from 3 to 9 years (mean 64 months). Overall success was achieved in $31 / 38$ patients $(82 \%)$. Meatal stenosis occurred in one patient $(3 \%)$, while urethrocutaneous fistulas developed in six (16\%).

Snodgrass popularized the use of TIP urethroplasty in redo hypospadias repairs and opined that TIP urethroplasty was an option whenever the urethral plate remained intact after the previous surgery and lacked gross scarring. [3] Shanberg and colleagues [14] too reported the use TIP urethroplasty in 13 redo cases with a mean follow-up of 22 months. Cosmetic results were excellent, with 2 complications: one patient with a glans dehiscence and a urethrocutaneous fistula, and a second patient who developed meatal stenosis. Ziada and colleagues retrospectively reviewed their series of 30 TIP reoperations after a mean of 1.6 prior repairs (range 1 to 3 ) in which $63 \%$ were distal. Suturing performed was subepithelial using polyglactin and covered with a dartos flap. During follow-up of more than 4 years there were nine complications (30\%): eight meatal stenoses (five with fistulas) and one isolated fistula. [15]

Kulkarni et al [16] reported that determining the type of urethroplasty to be performed depended on the following factors namely scarring of the urethral plate, width of urethral plate, width of glans, degree of chordee and ventral skin. Dorsal inlay graft technique is indicated whenever the urethral plate has been removed and only a strip of grossly healthy skin remained in its place. Snodgrass reported that only 16 patients $(12 \%)$ met the criteria for inlay grafts in their series of 133 reoperations. [17] The meatus was distal in $62 \%$ and the mean number of failed repairs was 1.9 (range 1 to 9). Indications were glans dehiscence in 15 patients and meatal stenosis with a diverticulum in 1 patient. Urethroplasty complications developed in 2 of 13 patients (15\%) with follow-up: one recurrent glans dehiscence and one fistula. [17] Ye and colleagues [18] reported their retrospective study of inlay grafts in 53 patients with an average of 2 failed repairs (range 1 to 6). Seventy percent had strictures; the remainder had glans dehiscence. Mean graft length was $5 \mathrm{~cm}$ taken from the lower lip. Urethroplasty com- plications occurred in 8 patients $(15 \%)$ during followup for a mean of 23 months: five fistulas and three recurrent strictures all at the proximal junction to the urethra.
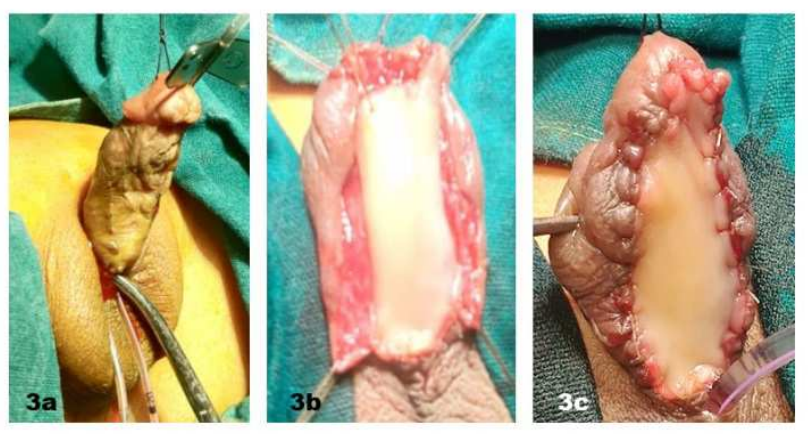

Figure 3. a. Gittes test in progress. b. Chordee corrected and buccal mucosa harvested. c. First stage buccal mucosa graft placed.
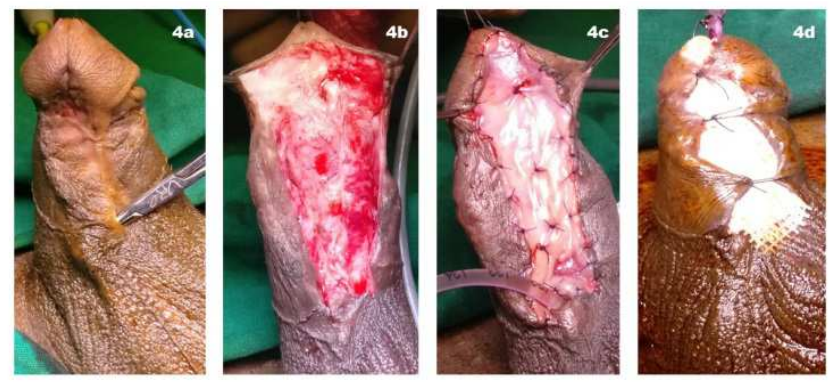

Figure 4. a. Shows scarred urethral plate with urethrocutaneous fistula. $b$. The scarred tissue and plate excised. c. Buccal mucosa harvested and placed over the site of urethral plate. d. First stage graft complete.

Two stage oral mucosa graft reoperation (Figure 3 and 4) is indicated whenever the urethral plate or skin substitute is grossly scarred, or the ventral curvature greater than 30 degrees, presence of Balanitis xerotica obliterans, strictures that nearly obliterate the lumen, or hair in the neourethra. $[19,20]$ There is no extra care necessary so as to revascularize the graft in between the two stages. It is necessary to wait for 6 months before performing the second stage of the urethroplasty. In less than $10 \%$ of cases the graft is known to scar or contract needing either partial or complete regrafting to be performed. [20] Kulkarni et al reported a graft contraction rate of $34 \%$ and believes that climacteric and ethnic factors had a role in graft contraction 
and the healing process. [20] Snodgrass and colleagues [17] needed additional grafting in 5 of 48 cases $(10 \%)$, requiring a patch in 4 and complete replacement in 1 . Nerli et al [19] reported on staged repair of redo hypospadias using buccal mucosa in 21 children aged $3-16$ years. Two of these 21 children had a failed first stage. One child developed a urethro-cutaneous fistula following the second stage, which was corrected in an additional stage.

Complications following repair of hypospadias, pose a challenge in the field of reconstructive urology. As of today there are no clear guidelines for the management of failed hypospadias repairs. Options include a TIP repair, Mathieu flip-flap urethroplasty, Dorsal inlay graft urethroplasty, ventral onlay flap urethroplasty and a two staged urethroplasty. There may always arise a need for subsequent procedures to deal with complications. Eventually if one persists in addressing this difficult problem then excellent functional and cosmetic results can be achieved.

\section{Conflict of Interest}

Authors declare conflict of interest as None.

\section{References}

[1] Wu M, Chen SZ, Ye WJ, Liu YD. Redo surgery for failed hypospadias treatment using a novel single-stage repair. Asian Journal of Andrology 2018; 20: 311-312.

[2] Al-Sayyad A, Pike JG, Leonard MP. Redo hypospadias repair: experience at a tertiary care children's hospital. Can Urol A J 2007; 1: 47-51.

[3] Snodgrass WT, Lorenzo A. Tubularized incised-plate urethroplasty for hypospadias reoperation. BJU Int 2002; 89: 98-100.

[4] Borer JG, Bauer SB, Peters CA, et al. Tubularized incised plate ure- throplasty: expanded use in primary and repeat surgery for hypospadias. J Urol 2001; 165: 581-5.

[5] Safwat AS, Elderwy A and Hammouda HM. Which type of urethroplasty in failed hypospadias repair? An 8-year followup. J Paed Urol 2013; 9: 1150-1154.

[6] Nerli RB, Guntaka AK, Patil RA, Patne PB. Dorsal inlay inner preputial graft for primary hypospadias repair. African Journal of Paediatric Surgery. 2014; 11 (2): 105.
[7] Manzoni G, Marrocco G. Reoperative hypospadias. Curr Opin Urol 2007; 17 (4): 268-71.

[8] Craig JR, Wallis C, Brant WO, Hotaling JM, Myers JB. Management of adults with prior failed hypospadias surgery. Transl Androl Urol. 2014; 3 (2): 196-204.

[9] Simmons GR, Cain MP, Casale AJ, et al. Repair of hypospadias complications using the previously utilized urethral plate. Urology 1999; 54: 724-6.

[10] Jayanthi VR, McLorie GA, Khoury AE, Churchill BM. Can previously relocated penile skin be successfully used for salvage hypospadias repair? J Urol 1994; 152: 740-3.

[11] Karabulut A, Sunay M, Erdem K, Emir L, Erol D. Retrospective analysis of the results obtained by using Mathieu and TIP urethroplasty techniques in recurrent hypospadias repairs. J Pediatr Urol 2008; 4: 359-63.

[12] Secrest CL, Jordan GH, Winslow BH, Horton CE, McCraw JB, Gilbert DA, et al. Repair of the complications of hypospadias surgery. J Urol 1993; 150: 1415-8.

[13] Anwar AZM, Hussein A, Shaaban AM, Abdel-Malek M. Modified Mathieu repair for failed surgery for hypospadias: Perimeatal-based flap with a subdermal vascular dartos pedicle. AfJ Urol 2015; 21: 100-104.

[14] Shanberg AM, Sanderson K, Duel B. Reoperative hypospadias repair using the Snodgass incised plate urethroplasty. BJU Int 2001; 87: 544-47.

[15] Ziada AM, Morsi H, Aref A, et al. Tubularized incised plate (TIP) in previously operated (redo) hypospadias. J Pediatr Urol 2006; 2: 409-14.

[16] Kulkarni SB, Joglekar O, Alkandari MH and Joshi PM. Redo hypospadias surgery: current and novel techniques. Reports and Research in Urology 2018; 10: 117-26.

[17] Snodgrass WT, Bush N, Cost N. Algorithm for comprehensive approach to hypospadias reoperation using 3 techniques. $J$ Urol 2009; 182: 2885-91.

[18] Ye WJ, Ping P, Liu YD, et al. Single stage dorsal inlay buccal mucosal graft with tubularized incised urethral plate technique for hypospadias reoperations. Asian J Androl 2008; 10: 682-6.

[19] Nerli RB, Neelagund SE, Guntaka A, Patil S, et al. Staged buccal mucosa urethroplasty in reoperative hypospadias. Indian journal of urology 2011; 27 (2): 196.

[20] Snodgrass WT and Bush NC. Hypospadias. In Wein AJ, Kavoussi LR, Partin AW and Peters CA, Eds, Campbell-Walsh Urology, 11th edition, Elsevier-Saunders, Philadelphia, $2016 \mathrm{p}$ 3399. 